\title{
Bioenergy Production from Wastes by Microalgae as Sustainable Approach for Waste Management and to Reduce Resources Depletion
}

\author{
Sibi G* \\ Department of Biotechnology, Indian Academy Degree College, India
}

Submission: July 05, 2018; Published: July 17, 2018

*Corresponding author: Sibi G, Department of Biotechnology, Indian Academy Degree College, Bangalore, India, Email: gsibii@gmail.com

\begin{abstract}
Immense increase in world population leads to endeavour the alternate energy sources and renewable sources have shown high potential in the production of biofuels. Bioenergy is a promising, sustainable source to combat the rising environmental, economic, and technological issues related to depleting fossil fuels. Algae are the most attractive feedstock for bioenergy than terrestrial crops and are well adapted to all ecosystems. Conversion of wastes to energy helps in resource conservation and environmental safety. Bioenergy production using wastewater, effluents, food and agricultural wastes as growth substrates for microalgal cultivation for both biomass and lipid production is one of the sustainable approach. This review presents the biomass and lipid production by microalgae cultivated in various wastes for effective waste management and to reduce the depletion of fossil fuel resources.
\end{abstract}

\section{Introduction}

Increasing global energy demand and depleting fossil fuel resources is an increasing concern worldwide. Resources and energy from wastes has increased significantly in the recent for reducing fossil fuel consumptions and resources depletion. Conversion of wastes to energy helps in resource conservation and environmental safety on a sustainable basis. Production of bioenergy using sustainable sources has been studied extensively due to diminishing fossil fuel reserves. Organic wastes are ideal and inexpensive substrates for microbial oil production by oleaginous microorganisms. Microalgae are regarded as the most promising feedstocks for biofuel production due to the advantages of higher oil content, higher rate of photosynthesis, no direct competition for agricultural land and easy cultivation. Use of organic wastes and wastewater as substrate for microalgae cultivation has potentials to produce microbial oils and to reduce nutrient concentrations in wastes. This review presents the biomass and lipid production by microalgae cultivated in various wastewater, food wastes and agricultural wastes for effective waste management and to reduce the depletion of fossil fuel resources.

\section{Waste Water}

Wastewater contains large number of nutrients and using microalgae to consume the nutrients in conjunction with waste water treatment is economically sustainable. Wastewater could be utilized to large scale microalgae-based biofuel production which substantially reduces the nutrient expenses and eater resources [1,2]. Wastewater including municipal wastewater, domestic wastewater, urban wastewater and digested animal manure effluents are used to cultivate microalgae for biomass and biofuel production. In a study by $\mathrm{Wu}$ involving industrial waste water, Chlamydomonas sp.TAI-2 has removed ammonium, nitrate and phosphorous with the lipid content of $18.4 \%$ [3] The better lipid accumulation properties (27.36 and 27.27\%) of Scenedesmus quadricauda SDEC-13 cultivated in waste water [4]. FAME analysis exhibited palmitic acid as the predominant constituent followed by oleic acid as second major component. The results indicated the use of sewage water as better substrate for biodiesel production than the chemical medium. In another study, Scenedesmus acutus cultivated in municipal waste water discharges resulted with biomass productivity and lipid accumulation of $79.9 \mathrm{mg} \mathrm{L}^{-1}$ and $282 \mathrm{mg} \mathrm{L}^{-1}$ respectively [5]. Investigations on Chlorella sorokiniana and Scenedesmus obliquus for nutrient removal and lipid production using sewage water was studied by Gupta [6]. S. obliquus demonstrated better lipid accumulation $(23.26 \% \mathrm{w} / \mathrm{w})$ than $C$. sorokiniana $(22.74 \% \mathrm{w} / \mathrm{v})$ thereby highlighting the algal species selection for wastewater treatment and lipid production. Integrating algae based biodiesel production with wastewater treatment using Auxenochlorella protothecoides UMN280 [7]. The results of batch cultivation showed high biomass $\left(269 \mathrm{mg} \mathrm{L}^{-1} \mathrm{~d}^{-1}\right)$ and lipid (78 $\mathrm{mg} \mathrm{L}^{-1} \mathrm{~d}^{-1}$ ) productivity. FAME analysis showed that lipids were mainly composed of C16/C18 fatty acids, which are suitable for biodiesel production. An increase in triacylglycerol production 
by Scenedesmus sp with increasing cultivation period using domestic wastewater was reported [8]. The lipid production was increased from $32 \mathrm{mg} \mathrm{L}^{-1}$ (21 days) to $148 \mathrm{mg} \mathrm{L}^{-1}$ (45 days)

in primary effluent. The capability of Chlorella sp utilizing meat processing water with biomass yield of 0.675-1.538 $\mathrm{g} \mathrm{L}^{-1}$ [9] (Table 1).

Table 1: Bioenergy production by microalgae using various waste resources.

\begin{tabular}{|c|c|c|}
\hline Microalgae & Substrate & Reference \\
\hline Neochloris oleoabundans & Dairy manure & Levine et al. [13] \\
\hline Chlorella sp & Digested manure & Hu et al. [31] \\
\hline Auxenochlorella protothecoides & Waste water & Zhou et al. [31] \\
\hline Chlamydomonas sp. & Industrial wastewater & Wu et al. [27] \\
\hline Chlorella protothecoides & Activated sludge & Wen et al. [26] \\
\hline Scenedesmus acutus & Municipal waste water & Sacristan de Alva et al. [21] \\
\hline Scenedesmus quadricauda & Waste water & Han et al. $[7,8]$ \\
\hline Scenedesmus sp. & Domestic wastewater & Zhang et al. [29] \\
\hline Chlorella vulgaris & Sewage sludge & Cho et al. [4] \\
\hline Chlorella sp. & Piggery wastewater & Kuo et al. [11] \\
\hline Chlorella vulgaris & Piggery wastewater & Marjakangas et al. [16] \\
\hline Scenedesmus bijuga & Anaerobically digested food Wastewater & Shin et al. [22] \\
\hline $\begin{array}{l}\text { Chlorella sorokiniana } \\
\text { Scenedesmus obliquus }\end{array}$ & Waste water & Gupta et al. [6] \\
\hline Porphyridium cruentum & Swine wastewater & Sandefur et al. (2016) \\
\hline Chlorella pyrenoidosa & Hydrolysate of food waste & Pleissner et al. [19] \\
\hline Chlorella vulgaris & Food waste & Lau et al. [12] \\
\hline Chlorella sorokiniana & Kitchen waste & Zhang et al. [28] \\
\hline Chlorella protothecoides & $\begin{array}{c}\text { Brewer fermentation } \\
\text { waste and crude glycerol }\end{array}$ & Feng et al. [5] \\
\hline Chlorella pyrenoidosa & Soybean processing wastewater & Hongyang et al. (2011) \\
\hline Chlorella vulgaris & Hydrolysate of Cyperus esculentus waste & Wang et al. [25] \\
\hline Chlorella protothecoides & Sugarcane bagasse hydrolysate & Mu et al. [17] \\
\hline Chlorella sp. Scenedesmus sp. & $\begin{array}{l}\text { Enzymatic hydrolysates of sweet sorghum and rice } \\
\text { straw }\end{array}$ & Sibi [23] \\
\hline Nannochloropsis sp. & Palm oil mill effluent & Cheirsilp et al. (2017) \\
\hline
\end{tabular}

Demonstrated nutrients in anaerobically digested activated sludge effluent can be remediated through assimilation into algal biomass with $2.43 \mathrm{~g} \mathrm{~L}^{-1}$ biomass concentration and $29.76 \%$ lipid content [10]. Heterotrophic cultivation of C. protothecoides using digested chicken manure filtrate yielded total lipid of $5.28 \mathrm{~g} \mathrm{~L}-1$ [11]. In another study, Chlorella sp was cultivated in piggery wastewater for a period of 10 days batch culture and resulted in $0.839 \mathrm{~d}-1$ and $0.681 \mathrm{~g} \mathrm{~L}^{-1} \mathrm{~d}^{-1}$ of specific growth rate and biomass productivity. The highest lipid content and lipid productivity were $29.3 \%$ and $0.155 \mathrm{~g} \mathrm{~L}^{-1} \mathrm{~d}^{-1}$ at $25 \%$ wastewater, respectively [12]. Hydrolysate obtained from ultrasonic pre-treatment of wasted activated sludge was used as an alternative carbon source for cultivation of Chlorella protothecoides. The lipid content of the culture was $21.5 \%$ with biomass yield of $0.5 \mathrm{~g} \mathrm{~L}^{-1}$ [13] indicating the use of activated sludge. Use of volatile fatty acids produced from sewage sludge fermentation system as carbon source for cultivation of Chlorella vulgaris was investigated [14]. The cultivation resulted in biomass productivity of $433 \pm 11.9$ $\mathrm{mg} \mathrm{L}^{-1} \mathrm{~d}^{-1}$ and lipid contents ranging from $12.87-20.01 \%$.
Waste substrate from brewer fermentation and crude glycerol were used as carbon and nitrogen source for the cultivation of $C$. protothecoides [15]. The lipid productivity of microalgae was compared with the basal medium and was observed higher in the waste substrate medium highlighting the alternative substrates for biofuel production. In a study by Hongyang, C. pyrenoidosa attained biomass productivity of 0.64 $\mathrm{g} \mathrm{L}^{-1} \mathrm{~d}^{-1}$ and lipid productivity of $0.40 \mathrm{~g} \mathrm{~L}^{-1} \mathrm{~d}^{-1}$ when cultivated in soybean processing waste water [16]. Neochloris oleoabudans grown in anaerobically digested dairy manure yielded $10-30 \%$ fatty acid methyl esters on dry with basis [17]. Hu reported that Chlorella sp. grown on acidogenically digested manure could be used as a feedstock for high-quality biodiesel production [18]. Marjakangas has examined the suitability of piggery wastewater as a nutrient source for production of lipid from C. vulgaris [19]. At diluted concentrations of wastewater, the biomass production decreased, and lipid content was increased. The highest lipid content and lipid productivity of $54.7 \mathrm{wt} \%$ and $100.7 \mathrm{mg} \mathrm{L}^{-1} \mathrm{~d}^{-1}$ was obtained with $20 \times$ and $5 \times$ dilution respectively. Immobilized 
cells of Nannochloropsis sp grown in secondary effluent of palm oil mill produced biomass and lipid production of $1.3 \mathrm{~g}$ $\mathrm{L}^{-1}$ and $0.356 \mathrm{~g} \mathrm{~L}^{-1}$, respectively. The repeated-batch cultivation improved the biomass and lipid production and the scale up in $3 \mathrm{~L}$-fluidized bed photobioreactor gave the maximum biomass of $3.28 \mathrm{~g} \mathrm{~L}^{-1}$ and lipid production of $0.36 \mathrm{~g} \mathrm{~L}^{-1}[20]$.

\section{Food Waste}

Food waste generated from vegetables, fruits, cereals, meat mainly consists of carbohydrates, proteins, lipids, and traces of inorganic compounds. The carbon footprint of food waste is estimated to contribute to the greenhouse gas emissions by accumulating approximately 3.3 billion tonnes of $\mathrm{CO} 2$ into the atmosphere per year. Incineration of food waste reduces hinders the recovery of nutrients and valuable chemical compounds thus reducing the economic value of the substrate and may cause severe health and environmental issues. Utilization of food waste as nutrient source for cultivating microorganisms offers to recycle organic matters and production of microbial value-added products. However, food wastes require a pretreatment step to recover low molecular weight nutrients, which the microalgae can easily assimilate.

Food waste hydrolysate was used as culture medium for Schizochytrium mangrovei and Chlorella pyrenoidosa in which 10-20 g microalgal biomass were produced [21]. Enzymatic hydrolysates of food waste were used for the cultivation of Chlorella pyrenoidosa by Plesissner [22]. Under nutrient sufficient batch culture, the cells of $C$. vulgaris contained $103.8 \mathrm{mg}$ $\mathrm{g}^{-1}$ lipids whereas it was three times higher in biomass cultured under phosphate/nitrogen limited conditions. The conversion of nutrients derived from food waste by $\mathrm{C}$. vulgaris with production of $200 \mathrm{mg} \mathrm{g}^{-1}$ lipids makes microalgae for recycling of food waste and fuel production [23]. Scenedesmus bijuga cultivated in food wastewater effluent has produced lipid content in the range of $13.81-15.59 \mathrm{mg} \mathrm{L}^{-1} \mathrm{~d}^{-1}$ which is higher than the cells grown in synthetic medium [24]. Similarly, biomass productivity was higher $\left(39.4-50.75 \mathrm{mg} \mathrm{L}^{-1} \mathrm{~d}^{-1}\right)$ in the microalgae when cultivated in diluted food wastewater effluent. Recent studies by Zhang demonstrated that anaerobically digested effluent from kitchen waste is a potential medium for cultivation of Chlorella sorokiniana and Scenedesmus sp with the optimal biomass productions of $0.42 \mathrm{~g} \mathrm{~L}^{-1}$ and $0.55 \mathrm{~g} \mathrm{~L}^{-1}$ [25]. When compared to the BG 11 medium, the lipid contents of $C$. sorokiniana and Scenedesmus grown in kitchen waste effluent were in the range of $30.27-41.69 \%$ and $35.97-47.39 \%$ respectively [26].

\section{Agricultural Waste}

Agricultural wastes can be utilized as a substrate for the cultivation of microalga due to their carbon and nitrogen content. Hydrolysates of sugarcane bagasse was used as a carbon source for the cultivation of Chlorella sp [27] and resulted in biomass concentration and lipid content of $5.8 \mathrm{~g} \mathrm{~L}^{-1}$ and $34.0 \%$ respectively. Enzymatic hydrolysates of sweet sorghum and rice straw were used for heterotrophic cultivation of Chlorella vulgaris and Scenedesmus obliquus. Maximum biomass was achieved in combined hydrolysates medium in C. vulgaris (4.8 $\mathrm{g} \mathrm{L}^{-1}$ ) followed by $S$. obliquus ( $4.3 \mathrm{~g} \mathrm{~L}^{-1}$ ). Total lipid content of Chlorella was ranged from 11.26-29.36 and 15.43-27.24\% in Scenedesmus. The qualitative analysis of fatty acids showed very high values of stearic acid (28.41 and $31.01 \%$ ) and palmitic acid (23.54 and 26.21\%) in both microalgae [28]. Hydrolysate of oil crop biomass residues was used to cultivate the microalgae to accumulate higher lipids [29]. Cyperus esculentus waste was used as the carbon source for C. vulgaris [30]. Fed-batch culture has produced maximum biomass, lipid content and lipid productivity of $20.75 \mathrm{~g} \mathrm{~L}^{-1}, 36.52 \%$, and $621.53 \mathrm{mg} \mathrm{L}^{-1} \mathrm{~d}^{-1}$ respectively [31].

\section{Conclusion}

Energy security, rising oil prices and economic objectives are stimulating a strong interest in the development of bioenergy. Biofuel production from microalgae using various waste water, food and agricultural wastes is economically feasible and sustainable approach. Chlorella $s p$ was reported to grow in wide range of waste water and organic wastes for the production of biomass and lipid. However, considering the complexity and nutrient variations among different wastes, there is a need to conduct productivity and techno-economic analysis for the sustainable bioenergy production using microalgae on a larger scale.

\section{References}

1. Cheah WY, TC Ling, PL Show, JC Juan, JS Chang, et al. (2016) Cultivation in wastewaters for energy: A microalgae platform. Appl Energy 179: 609-625.

2. Cheirsil B, Thawechai T, Prasertsan P (2017) Immobilized oleaginous microalgae for production of lipid and phytoremediation of secondary effluent from palm oil mill in fluidized bed photobioreactor. Bioresour Technol 241: 787-794.

3. Chen GL, Zhao Y Qi (2015) Enhancing the productivity of microalgae cultivated in wastewater toward biofuel production: a critical review. Appl Energy 137: 282-291.

4. Cho HU, Kim YM, Choi Y, Xu X, Shin DY, et al. (2015) Effects of pH control and concentration on microbial oil production from Chlorella vulgaris cultivated in the effluent of a low-cost organic waste fermentation system producing volatile fatty acids. Bioresour Technol 184: 245-250.

5. Feng X, Walker TH, Bridges WC, Thornton C, Gopalakrishnan K (2014) Biomass and lipid production of Chlorella protothecoides under heterotrophic cultivation on a mixed waste substrate of brewer fermentation and crude glycerol. Bioresour Technol 166: 17-23.

6. Gupta SK, Ansari FA, Shriwastav A, Sahoo NK, Rawat I (2016) Dual role of Chlorella sorokiniana and Scenedesmus obliquus for comprehensive wastewater treatment and biomass production for bio fuels. Journal of Cleaner Production 115: 255-264.

7. Han L, Pei H, Hu W, Han F, Song M, et al. (2014) Nutrient removal and lipid accumulation properties of newly isolated microalgal strains. Bioresour Technol 165: 38-41.

8. Han L, Pei H, Hu W, Jiang L, Ma G, et al. (2015) Integrated campus sewage treatment and biomass production by Scenedesmus quadricauda SDEC-13. Bioresour Technol 175: 262-268. 
9. Honhyang S, Yalei Z, Chunmin Z, Xuefei Z, Jinpeng L (2011) Cultivation of Chlorella pyrenoidosa in soybean processing wastewater. Bioresour Technol 102: 9884-9890.

10. Hu B, Min M, Zhou W, Du Z, Mohr M, et al. (2012) Enhanced mixotrophic growth of microalga Chlorella sp. on pretreated swine manure for simultaneous biofuel feedstock production and nutrient removal Bioresour Technol 126: 71-79.

11. Kuo CM, Chen TY, Lin TH, Kao CY, Lai JT, et al. (2015) Cultivation of Chlorella sp. GD using piggery wastewater for biomass and lipid production. Bioresour Technol 194: 326-333.

12. Lau KY, Pleissner D, Lin CSK (2014) Recycling of food waste as nutrients in Chlorella vulgaris cultivation. Bioresour Technol 170: 144-151.

13. Levine RB, Costanza Robinson MS, Spatafora GA (2011) Neochloris oleoabundans grown on anaerobically digested dairy manure for concomitant nutrient removal and biodiesel feedstock production. Biomass Bioenerg 35(1): 40-49.

14. Liang GB, YW Mo, QF Zhou (2013) Optimization of digested chicken manure filtrate supplementation for lipid overproduction in heterotrophic culture Chlorella prototheorids. Fuel 108: 159-165.

15. Lu Q Zhou W, Min M, Ma X, Chandra C, et al. (2015) Growing Chlorella sp on meat processing wastewater for nutrient removal and biomass production. Bioresour Technol 198: 189-197.

16. Marjakangas JM, CY Chen, AM Lakaniemi, JA Puhakka, LM Whang, et al. (2015) Selecting an indigenous microalgal strain for lipid production in anaerobically treated piggery wastewater. Bioresour Technol 191: 369-376.

17. Mu J, Li S, Chen D, Xu H, Han F, et al. (2015) Enhanced biomass and oil production from sugarcane bagasse hydrolysate (SBH) by heterotrophic oleaginous microalga Chlorella protothecoides. Bioresour Technol 185: 99-105.

18. Park S, Y Li (2012) Evaluation of methane production and macronutrient degradation in the anaerobic co-digestion of algae biomass residue and lipid waste. Bioresource Technology 111: 42-48.

19. Pleissner D, Lau KY, Carol Sze, Ki Lin CSK(2017) Utilization of food waste in continuous flow cultures of the heterotrophic microalga Chlorella pyrenoidosa for saturated and unsaturated fatty acids production Journal of Cleaner Production 142: 1417-1424.

20. Pleissner D, Lam WC, Sun Z, Lin CSK (2013) Food waste as nutrient source in heterotrophic microalgae cultivation. Bioresour Technol 137: 139-146.

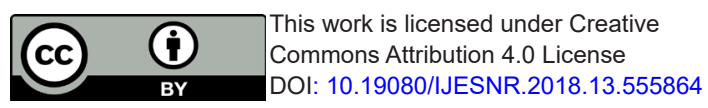

21. Sacristan de Alva M, Luna Pabello VM, Cadena E, Ortiz E (2013) Green microalga Scenedesmus acutus grown on municipal wastewater to couple nutrient removal with lipid accumulation for biodiesel production. Bioresour Technol 146: 744-748.

22. Shin DY, Cho HU, Utomo JC, Choi YN, Xu X, et al. (2015) Biodiesel production from Scenedesmus bijuga grown in anaerobically digested food wastewater effluent. Bioresour Technol 184: 215-221.

23. Sibi G (2015) Low cost carbon and nitrogen sources for higher microalgal biomass and lipid production using agricultural wastes. Journal of Environmental Science and Technology 8(3): 113-121.

24. Tan XB, YL Zhang, LB Yang, HQ Chu J, Guo (2016) Outdoor cultures of Chlorella pyrenoidosa in the effluent of anaerobically digested activated sludge: the effects of $\mathrm{pH}$ and free ammonia, Bioresour Technol 200: 606-615.

25. Wang W, Zhou W, Liu J, Li Y, Zhang Y (2013) Biodiesel production from hydrolysate of Cyperus esculentus waste by Chlorella vulgaris. Bioresour Technol 136: 24-29.

26. Wen Q, Chen, Li P, Duan R, Ren N (2013) Lipid production for biofuels from hydrolysate of waste activated sludge by heterotrophic Chlorella proto thecoides. Bioresour Technol 143: 695-698.

27. Wu LF, Chen PC, Huang AP, Le CM (2012) The feasibility of biodiesel production by microalgae using industrial wastewater. Bioresour Technol 113: 14-18.

28. Zhang L, Cheng J, Pei H, Pan J, Jiang L, et al. (2018) Cultivation of microalgae using anaerobically digested effluent from kitchen waste as a nutrient source for biodiesel production. Renewable Energy 115: 276-287.

29. Zhang TY, Wu YH, Hu HY (2014) Domestic wastewater treatment and biofuel production by using microalga Scenedesmus sp. ZTY1 Water Sci Technol 69(12): 2492-2496

30. Zhong WL, Chi Y, Luo Z, Zhang Z, Zhang, et al. (2013) Enhanced methane production from Taihu Lake blue algae by anaerobic co-digestion with corn straw in continuous feed digesters. Bioresource Technology 134 264-270.

31. Zhou W, Li Y, Min M, Hu B, Zhang H, et al. (2012) Growing wastewaterborn microalga Auxenochlorella protothecoides UMN280 on concentrated municipal wastewater for simultaneous nutrient removal and energy feedstock production. Applied Energy 98: 433-440.

\section{Your next submission with Juniper Publishers will reach you the below assets}

- Quality Editorial service

- Swift Peer Review

- Reprints availability

- E-prints Service

- Manuscript Podcast for convenient understanding

- Global attainment for your research

- Manuscript accessibility in different formats

( Pdf, E-pub, Full Text, Audio)

- Unceasing customer service

Track the below URL for one-step submission https://juniperpublishers.com/online-submission.php 